Monique Souza*, Jucinei José Comin, Rodolfo Moresco, Marcelo Maraschin, Claudinei Kurtz, Paulo Emílio Lovato, Cledimar Rogério Lourenzi, Fernanda Kokowicz Pilatti, Arcângelo Loss and Shirley Kuhnen

\title{
Exploratory and discriminant analysis of plant phenolic profiles obtained by UV-vis scanning spectroscopy
}

https://doi.org/10.1515/jib-2019-0056

Received July 29, 2019; accepted April 26, 2021; published online June 4, 2021

\begin{abstract}
Some species of cover crops produce phenolic compounds with allelopathic potential. The use of math, statistical and computational tools to analyze data obtained with spectrophotometry can assist in the chemical profile discrimination to choose which species and cultivation are the best for weed management purposes. The aim of this study was to perform exploratory and discriminant analysis using $\mathrm{R}$ package specmine on the phenolic profile of Secale cereale L., Avena strigos a L. and Raphanus sativus L. shoots obtained by UV-vis scanning spectrophotometry. Plants were collected at 60, 80 and 100 days after sowing and at 15 and 30 days after rolling in experiment in Brazil. Exploratory and discriminant analysis, namely principal component analysis, hierarchical clustering analysis, $t$-test, fold-change, analysis of variance and supervised machine learning analysis were performed. Results showed a stronger tendency to cluster phenolic profiles according to plant species rather than crop management system, period of sampling or plant phenologic stage. PCA analysis showed a strong distinction of S. cereale L. and A. strigosa L. 30 days after rolling. Due to the fast analysis and friendly use, the $\mathrm{R}$ package specmine can be recommended as a supporting tool to exploratory and discriminatory analysis of multivariate data.
\end{abstract}

Keywords: chemometrics; cover crops; multivariate analysis; R language; specmine.

\section{Introduction}

Scanning UV-vis spectrophotometry has many advantages on the analysis of plant extracts. Among them, it can be highlighted the small amount of sample required, easy preparation of the samples and fast data acquisition, especially that related to specific classes of secondary metabolites [1, 2], such as phenolic compounds [3-5].

\footnotetext{
* Corresponding author: Monique Souza, Universidade Federal de Santa Catarina, Departamento de Engenharia Rural, Rodovia Admar Gonzaga. 1346, Florianópolis, Santa Catarina 88034-000, Brazil, E-mail: monique_souzaaa@yahoo.com.br Jucinei José Comin, Marcelo Maraschin, Paulo Emílio Lovato, Cledimar Rogério Lourenzi, Arcângelo Loss and Shirley Kuhnen, Universidade Federal de Santa Catarina, Florianopolis, Brazil. https://orcid.org/0000-0002-6176-6208 (J. José Comin), https://orcid.org/0000-0002-4146-4835 (M. Maraschin), https://orcid.org/0000-0001-5828-696X (P. Emílio Lovato), https://orcid.org/0000-0002-0347-0003 (C. Rogério Lourenzi), https://orcid.org/0000-0002-3005-6158 (A. Loss), https://orcid.org/0000-0002-1882-5241(S. Kuhnen)

Rodolfo Moresco, Escola do Mar, Ciência e Tecnologia da Universidade do Vale do Itajaí, (UNIVALI), Itajaí, Brazil. https://orcid .org/0000-0001-9703-4220

Claudinei Kurtz, EPAGRI, Ituporanga, Santa Catarina, Brazil. https://orcid.org/0000-0002-1688-6139

Fernanda Kokowicz Pilatti, Instituto Federal Sul-rio-grandense, Pelotas, RS, Brazil. https://orcid.org/0000-0003-0103-7975
}

๖ Open Access. (2021 Monique Souza et al., published by De Gruyter. (C) BY 4.0 International License. 
Some species of angiosperms used as cover crops, like black oat (Avena strigosa L.) and rye (Secale cereale L.), both from Poaceae family, and oilseed radish (Raphanus sativus L.) from Brassicaceae family, are known for producing phenolic compounds, particularly related to weeds control [4-8].

Most of the studies addressing these compounds aim on their quantification [9, 10], but few explore chemical data from UV-vis profiles to discriminate species according to their phenolic composition.

Spectroscopic methods that use wavelengths, like UV-vis and infrared, are faster and require less or no chemical processing, compared to chromatographic methods. With the support of mathematical and statistical tools, it is possible to process spectra and identify patterns of metabolic fingerprints, enabling to discriminate samples according to their similar or disparate characteristics [11].

Spectra obtained by UV - vis scanning spectrophotometry usually have many peaks the occasional similarity of sample profiles make essential the use of bioinformatic tools, such as discriminatory analysis, in order to obtain important and additional information $[2,12,13]$. Using the datasets of spectrophotometric profiles, it is possible to build descriptive and classification models that enable to explore those profiles. The application of mathematical and statistical methods, such as univariate and multivariate analysis, in association with complementary techniques for the detection of compounds, for example, spectrometry (UV-vis, NIR, NMR), are useful tools to assist in the characterization and discrimination of samples in the Chemistry field [14-18].

In this context, with the application of chemometric methods it is possible to investigate, interpret, classify and separate spectra profiles of complex matrices, pre-processed or not, within any range of the spectrum, acquired with UV-vis spectrophotometry, infrared spectroscopy or nuclear magnetic resonance $[15,19,20]$. Due to the volume of information and the complexity of data, the most popular approaches to identify global differences between the samples include non-supervised methods, like principal component analysis (PCA) and hierarchical clustering analysis (HCA) [16, 21].

Aiming to simplify the analysis of spectral profiles and the prospecting of big datasets, the use of free computational environments, like the $\mathrm{R}$ language and its biostatistics packages and tools, can help to comprehend the relations between the variables under analysis. Our hypothesis is that the use of these tools will enable to identify spectral regions that discriminate the phenolic profiles according to features such as plant species, phenological stage, and farming conditions.

In this sense, the aim of this work was to perform exploratory and discriminatory analysis on phenolic profiles of S. cereale L. A. strigosa L. and R. sativus L. shoots obtained by UV-vis scanning spectrophotometry.

\section{Materials and methods}

\subsection{Samples}

The experiment was conducted at the Experimental Station of the Company of Agriculture Research and Rural Extension of Santa Catarina (EPAGRI) in the city of Ituporanga, Santa Catarina State ( $27^{\circ} 24^{\prime} 52^{\prime \prime}, 49^{\circ} 36^{\prime} 9^{\prime \prime}$ and altitude $475 \mathrm{~m}$ ). The climate of the region is humid subtropical (Cfa), according to the Köppen classification, with a mean annual temperature of $17.6^{\circ} \mathrm{C}$ and a mean annual rainfall of $1.400 \mathrm{~mm}$. The soil of the area was classified as Humic Dystrudept [22].

The experiment was installed in an area with a 20-year history of onion cultivation under conventional tillage (CT) (plowing, harrowing, and scarification) until 1996. From 1996 to 2007, a minimum cultivation system was implemented for onion in rotation with the following cover crop species: black oat (A. strigosa Schreb), velvet bean (Mucuna aterima Piper \& Tracy), millet (Pennisetum glaucum L.), sunn hemp (Crotalaria juncea L.), and vetch (Vicia sativa L.). The area was then grown with sweet potato (Ipomoea batatas (L.) Lam.) until 2009, when the non-tillage (NT) experiment with onion was installed. The weeds were desiccated with glyphosate at the beginning of the experiment (April 2009).

Five treatments were used for winter cover crop, considering plant species and crop management system (single or intercropped): black oat (120 kg of seeds ha $\left.{ }^{-1}\right)$; rye (120 kg of seeds ha $\left.{ }^{-1}\right)$; oilseed radish $\left(20 \mathrm{~kg}_{\text {of seeds ha }}{ }^{-1}\right)(\mathrm{NF})$; oilseed radish (10 $\mathrm{kg}$ of seeds ha $\left.{ }^{-1}\right)+$ rye $\left(60 \mathrm{~kg}\right.$ of seeds ha- $\left.{ }^{-1}\right)$; oilseed radish $\left(10 \mathrm{~kg}\right.$ of seeds ha $\left.{ }^{-1}\right)+$ black oat $\left(60 \mathrm{~kg}\right.$ of seeds ha $\left.{ }^{-1}\right)$. The seeds of these winter species were sown every year in April. The seeds were sown by hand on the soil surface. There was no fertilization, irrigation, or crop management during the cover crop cycles. In 2014, single and intercropped rye shoots were collected at five periods: 60, 80 and 100 days after sowing (DAS) and 15 and 30 days after rolling (DAR). Oilseed radish single and intercropped (rye and black oat) were collected at four periods: 60, 80 and 100 days after sowing (DAS) and 15 days after rolling (DAR). Black oat, single and intercropped, was collected only at three periods: 100 DAS and 15 and 30 DAR. Three subsamples were randomly 
collected from each plot to make one composed sample. Each species was separately collected and later evaluated, including those from the intercrops. The experimental design was randomized blocks with three replicates. The area of each experimental plot was $5 \times 5 \mathrm{~m}^{2}$.

A total of 84 samples were collected from the field experiment, identified, put in falcon tubes $(50 \mathrm{~mL})$ and kept in a Styrofoam thermal box with dry ice during the transport to the laboratory. Samples were lyophilized at $-54{ }^{\circ} \mathrm{C}$ (model L101, Liotop, São Paulo, Brazil) until total removal of moisture, pulverized, sieved $(0.42 \mathrm{~mm})$ and kept at $-20^{\circ} \mathrm{C}$ until analysis.

\subsection{Extraction and analysis through scanning UV-vis spectrophotometry}

For the extracts, the plant material was macerated with methanol (Vetec) $80 \%$ (v/v) (1:50, w/v), shaken for $2 \mathrm{~h}$ and filtered under vacuum. The extracts were then centrifuged at $4000 \mathrm{rpm}$ for $15 \mathrm{~min}$. The supernatants were collected and subjected to UV-vis scanning spectrophotometry (model UV-5300PC, Power Supply, China), for the acquisition of spectral profiles (200-800 nm). Each sample was scanned three times, resulting in a dataset with 252 spectral profiles.

\subsection{Chemometric analysis}

All the analyses were performed using $\mathrm{R}$ language $\left(\mathrm{R}^{\odot} \mathrm{v}\right.$. 3.3.1) [23] with R Studio, and tools and functions available in the package 'specmine' [24]. All the scripts were written with the package R Markdown and the reports were automatically generated. Two data sheets were created, one named "metadata", holding information about treatments (plant species and crop management system) and periods of sampling, and other named "data", containing data from the spectral profiles in the range of 200-800 nm, both saved in the "xlsx" format. To import those data sheets into the R environment, both files were converted to "csv" format.

'specmine' is an R package with functions that enable to perform univariate analysis to big data set with hundreds of variables, in example, the wavelengths from our data. Thus, data obtained from the UV-vis spectral profiles was subjected to univariate statistics $t$ test, fold-change test and analysis of variance (ANOVA), and to the multivariate unsupervised methods principal components analysis (PCA) and hierarchical cluster analysis from correlated matrices. Supervised machine learning based on partial least squares regression (PLS) and k-nearest neighbor (knn) models were applied to the dataset to determine the best predictive model for sample classification. The error estimation method was repeated by 10 -fold cross-validation and 10 repetitions.

\section{Results and discussion}

With the tools from the package specmine it is possible to explore the whole spectral region obtained via UV-vis spectroscopy in the dataset or to crop specific regions, depending on the compounds to be analyzed and the aim of the research. In the present work, the spectral profiles in the region $200-800 \mathrm{~nm}$ from the shoots of rye, black oat and oilseed radish, grown single or intercropped, at 60, 80 and 100 DAS and 15 and 30 DAR were evaluated (Figure $1 \mathrm{~A}-\mathrm{C}$ ) and the region of 200-400 nm (Figure 1D-F) was cropped to be used in some analysis.

Initially the analysis of the 84 spectra showed similar profiles between the samples and the highest values of absorbance in the region of $200-400 \mathrm{~nm}$ (Figure $1 \mathrm{~A}-\mathrm{C}$ ), which is the region attributed to the phenolic compounds. Most of the phenolic compounds and flavonoids have their absorption range around $280 \mathrm{~nm}$ $[25,26]$. This was supported by the fold-change analysis (Figure 2).

The fold-change analysis is usually used in analysis of profiles and when multiple measurements are being analyzed $[2,11,27]$. In this study, the fold-change analysis indicated difference between rye, oilseed radish and black oat in the region of $300-450 \mathrm{~nm}$, the typical region of absorbance of phenolic compounds and carotenoids. In addition, some signals in the region of 650-700 nm, typical region of absorbance of the chlorophylls, had significant signal intensity (Figure 2).

This approach corroborates the univariate analysis performed on the spectra, expressed via statistical significance of the model by the descriptive $p$-value. In fact, the wavelengths with the lowest $p$-values were observed in the spectral window of 300-420 nm (data available in the supplementary material). Samples showed intense absorbance in the wavelength regions assigned to the phenolic compounds (Figure 1A), corroborating literature that reports that these compounds as commonly present in black oat, rye and oilseed radish $[7,8,28,29]$. Thus, although small discrepancies between the profiles exist, they are difficult to be 
(A)

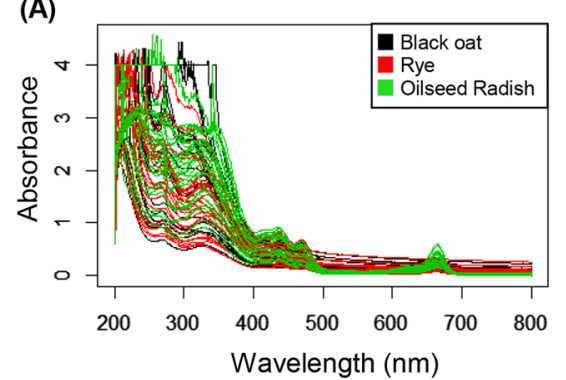

(B)

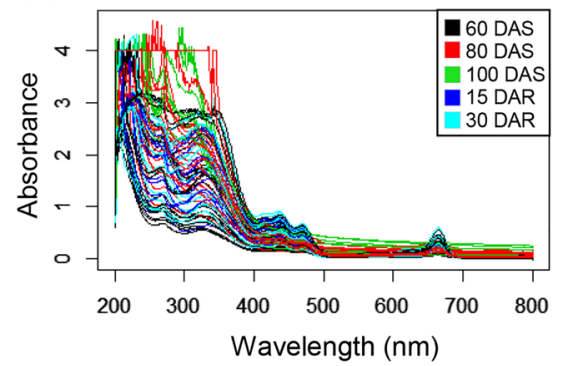

(C)

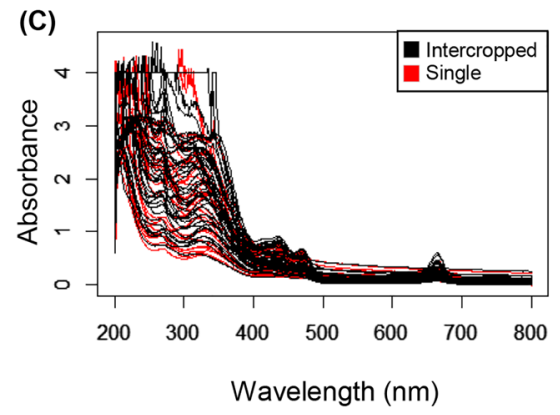

(D)

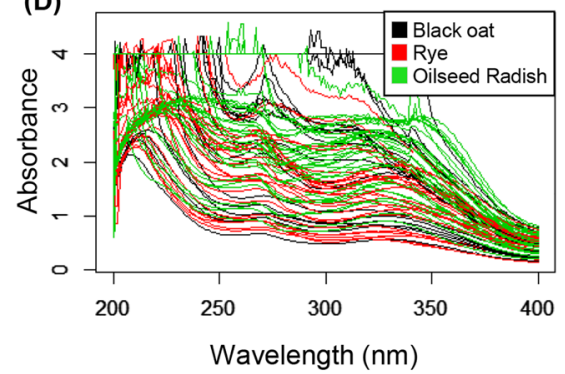

(E)

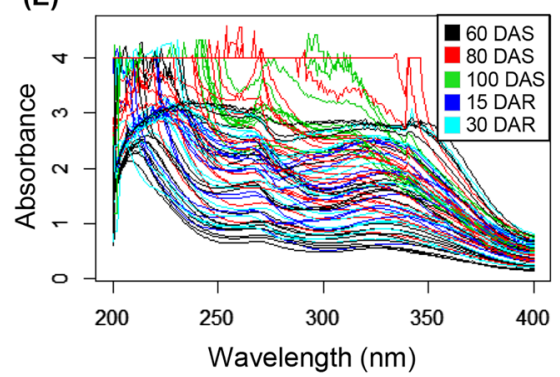

(F)

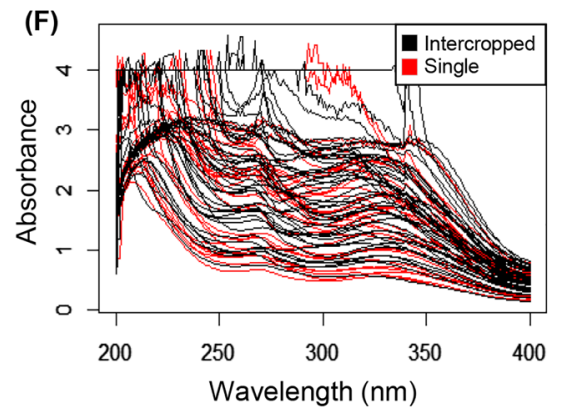

Figure 1: UV-vis spectra profiles of the methanolic extract of plant shoots in the region of 200-800 nm before pre-processing $(\mathrm{A}-\mathrm{C})$ and 200-400 nm (D-F). The colors of the spectra indicate the plant species black oat (Avena strigosa L.), rye (Secale cereale L.) and oilseed radish (Raphanus sativus L.) (A and D), the periods of sampling (days after sowing-DAS and days after rolling-DAR) (B and E) and crop management system (single or intercropped) (C and F).

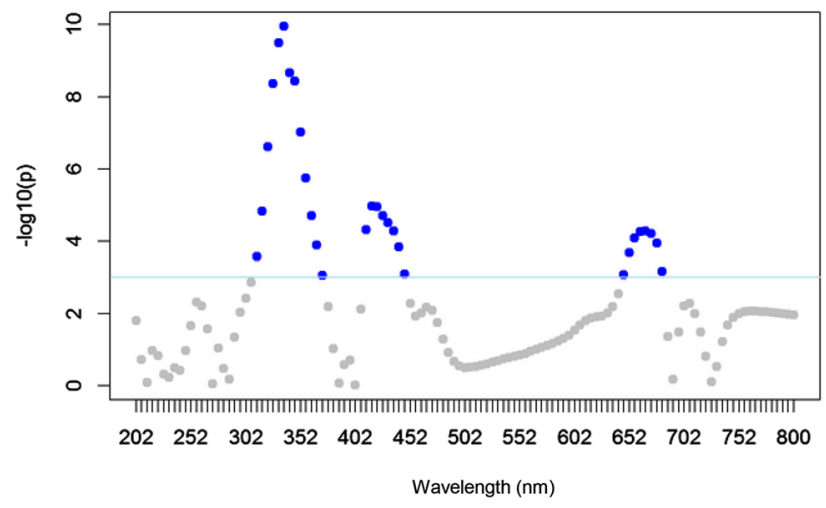

Figure 2: Fold-change analysis of the UV-vis spectra dataset $(200-800 \mathrm{~nm})$. Blue dots indicate wavelengths with significant differences $(p<0.05)$. Samples were statistically different in the region between 300 and 450 $\mathrm{nm}$ (phenolic compounds and carotenoids) and 650-700 $\mathrm{nm}$ (chlorophylls).

identified. At first sight, the spectra overlaps might suggest similarity in the chemical composition of the species, so it is necessary to use tools that help to interpret data.

Language $\mathrm{R}$ has packages and functions with mathematical tools to transform, pre-process signals and spectra, like specmine. In this study the pre-processing was used to baseline correction, smoothing and cropping (200-400 nm) to the spectra (Figure $3 \mathrm{~A}-\mathrm{C}$ ). Although it was possible to identify statistical differences and discriminate samples when the dataset was analyzed globally or cropped, the clusters obtained after preprocessing can reinforce the similarity between the samples previously observed or bring new information for subsequent analysis [11]. 

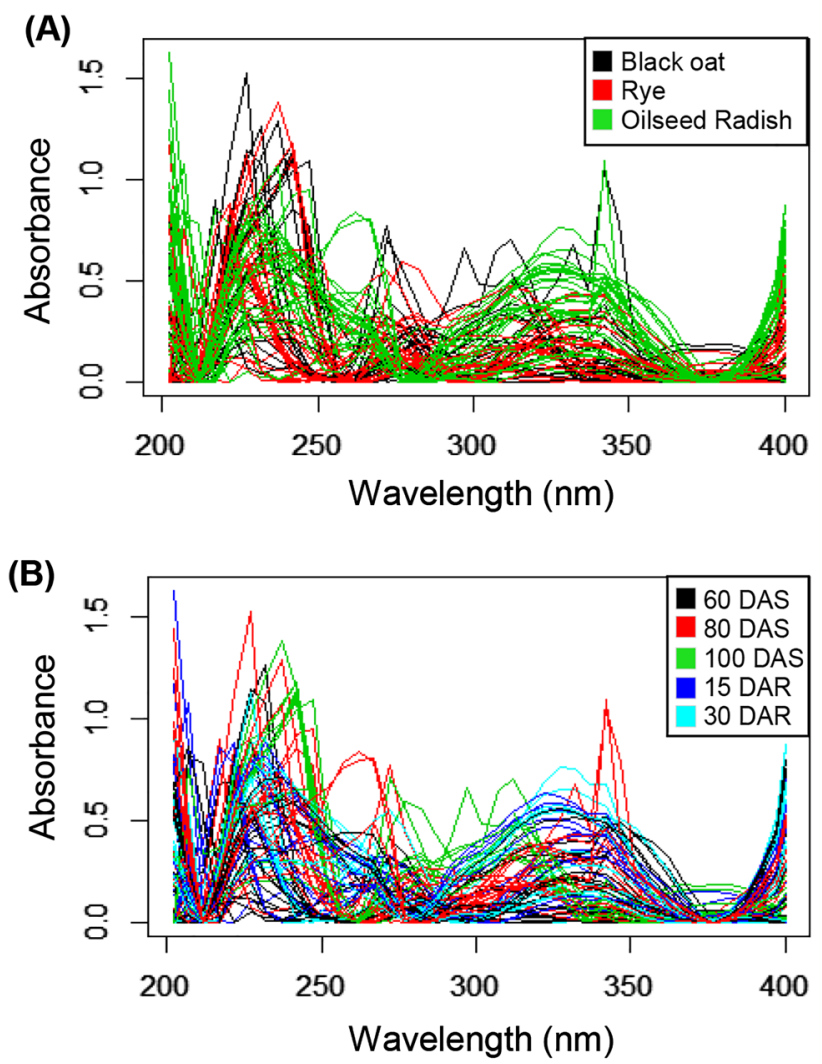

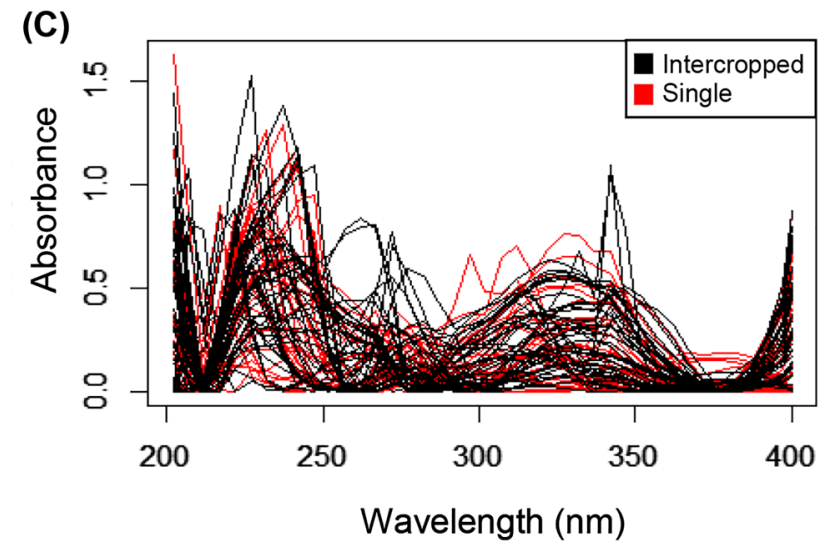

Figure 3: UV-vis spectra profiles of the methanolic extract of plant shoots in the region of $200-400 \mathrm{~nm}$ after pre-processing. The colors of the spectra indicate the plant species black oat (Avena strigosa L.), rye (Secale cereale $\mathrm{L}$.) and oilseed radish (Raphanus sativus L.) (A), the periods of sampling (days after sowing-DAS and days after rolling-DAR) (B) and crop management system (single or intercropped) (C).

Based on the information obtained observing the plots, different statistical analysis, like multivariate analysis and hierarchical clustering, were performed on the entire spectral region and in the region between 200 and $400 \mathrm{~nm}$, aiming to detect differences between the profiles in the spectral region related to the phenolic compounds [30]. The spectral profile of oilseed radish was different from those of rye and black oat, which were similar to each other (Figure 3A). Regarding to the time of cropping when the samples were collected, only the samples collected at 30 DAR segregated in the hierarchical clustering (Figure 4B).

Next, with the principal component analysis, it was possible to see how the samples clustered according to their differences and similarities based on UV-vis spectral data, with dimensionality reduction of the dataset but preserving the information and calculating linear combinations between the original variables [31]. Thus, the present study performed PCA on the UV-vis spectral profiles after pre-processing the region between 200 and $400 \mathrm{~nm}$ to assess clusters based on differences or similarities in the phenolic composition 
(A)
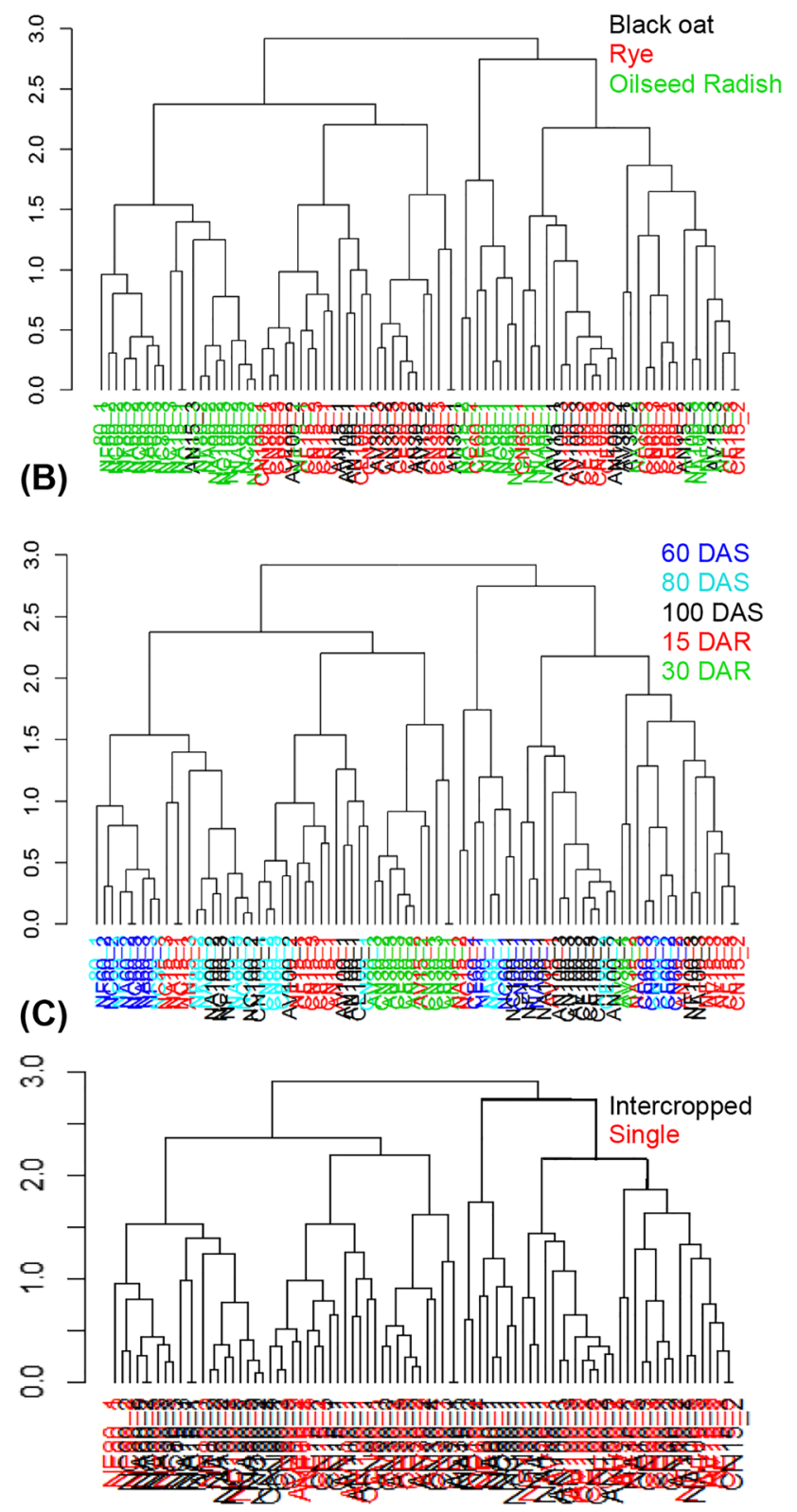

Figure 4: Dendrograms of UV-vis spectra in the region of 200-400 $\mathrm{nm}$ after hierarchical clustering analysis using the Euclidean distance. Colors indicate plant species (A), period of sampling (days after sowing-DAS and days after rolling-DAR) (B) and crop management system (C).

of the samples. Figure 5 shows the score plot from the PCA performed on the same dataset used in the hierarchical clustering analysis (Figure 4) for rye, black oat and oilseed radish samples.

In the PCA of the spectral profiles, PC1 and PC2 explained 55.4\% of the variance in the data, segregating single and intercropped oilseed radish from the Poaceae black oat and rye. These results point to a distinction between these species concerning to their phenolic composition as well as other compounds that absorb in the UV range (Figure 5A). Rye samples, for all the evaluation times, are situated at the score plot PC1(-), while rye and black oat samples at 60,80 and $100 \mathrm{DAS}$ are at $\mathrm{PC} 1(+)$. Rye and black oat samples after rolling are at $\mathrm{PC} 1(+)$ and PC2(-) (Figure 5A). The wavelengths that had greater contribution for the clustering were 252, 257, 282, 352, 392 and $397 \mathrm{~nm}(p<0.05)$ (Figure 6A). The oilseed radish, a member of the Brassicaceae family, is known for its allelopathic activity and phenolic compounds production [29,32], which are mainly concentrated in the shoots [33], in contrast to members of Poaceae, such as black oat and rye, which concentrates those 


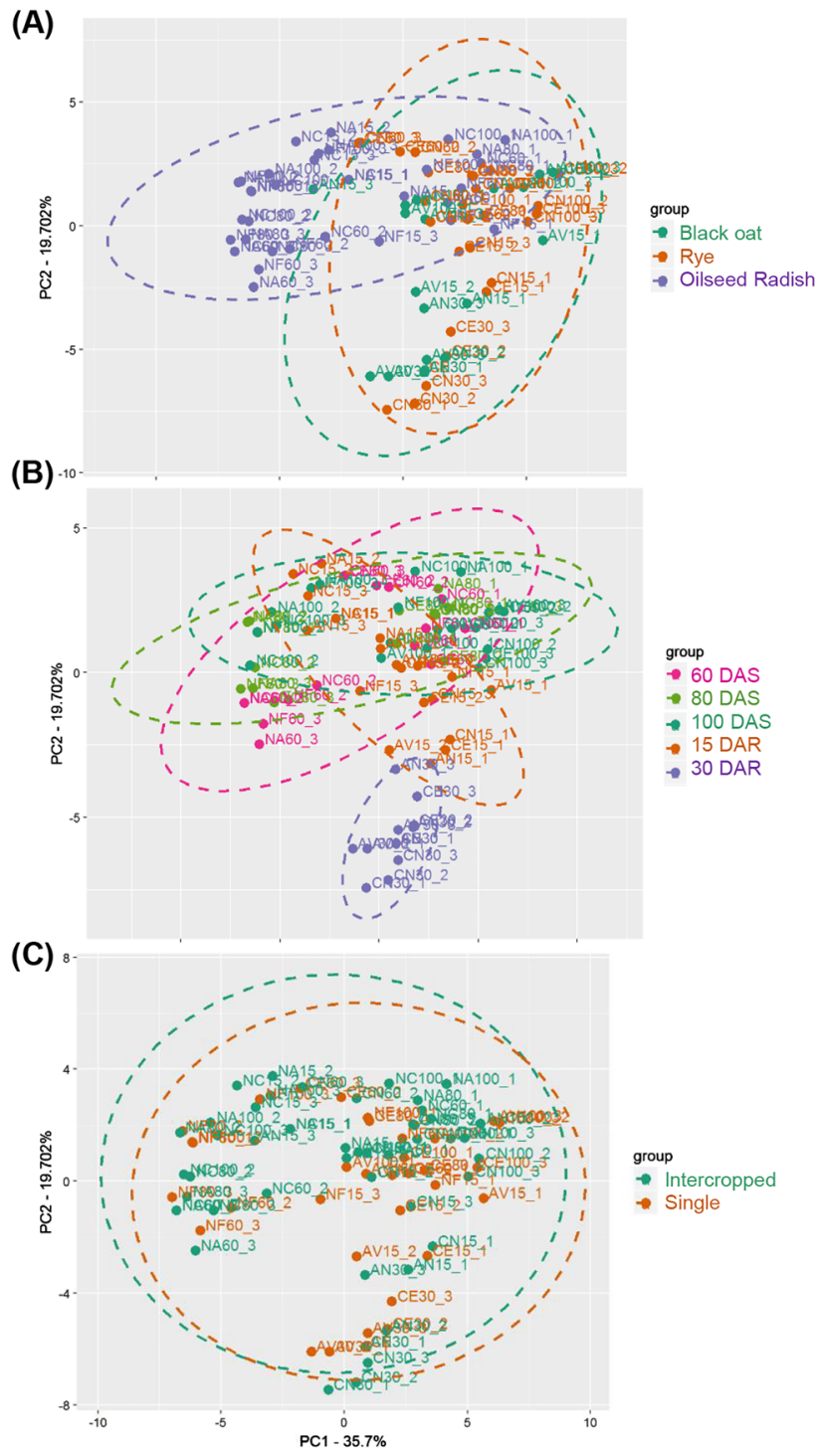

Figure 5: Factorial distribution of principal components 1 (PC1) and 2 (PC2) of the UV-vis spectral profiles of plant methanolic extracts in the region of absorbance of phenolic compounds (200-400 nm) after preprocessing. Colors indicate plant species $(A)$, periods of sampling (days after sowing-DAS and days after rolling-DAR) (B) and crop management system (single or intercropped) (C).

compounds in their roots and other organs, for example, the grains [28, 34, 35]. Concerning to the periods when the samples were collected, species collected at 30 DAR segregated from those collected at 60, 80 and 100 DAS and 15 DAR (Figure 5B). The wavelengths that contributed the most for that segregation were 237, 242, 287, 297, 302 and $312 \mathrm{~nm}$ (Figure 6B). The overlapping of samples collected at different periods at the score plot $\mathrm{PC} 2(+)$ indicate similarity between those and distinction from the samples collected at 30 DAR, which segregated at PC2(-) (Figure 5B), suggesting that black oat, rye and oilseed radish phenolic profile at 60, 80 and 100 DAS share more similarities then the profiles of these plants after rolling. This result due to the changes in the chemical composition of the plant material after longer time for sampling, 30 days after rolling, when plant material have longer period of degradation and the releasing of phenolic compounds [36]. Secondary metabolites profiles, such as phenolic compounds, vary in quality and quantity depending on many factors, including weather condition, plant age, and methods for extractions and analysis [37]. In a study on total phenolic compounds in rye [34], reported differences related to the phenological stage in the content of five phenolic acids, with the highest contents at 22 days after blooming and the lowest contents during grain maturation. Furthermore, some phenolic acids are probably related to lignification process, which occurs after rolling. Due to its lower $\mathrm{C} / \mathrm{N}$ ratio and higher mineralization rate, the oilseed radish is 


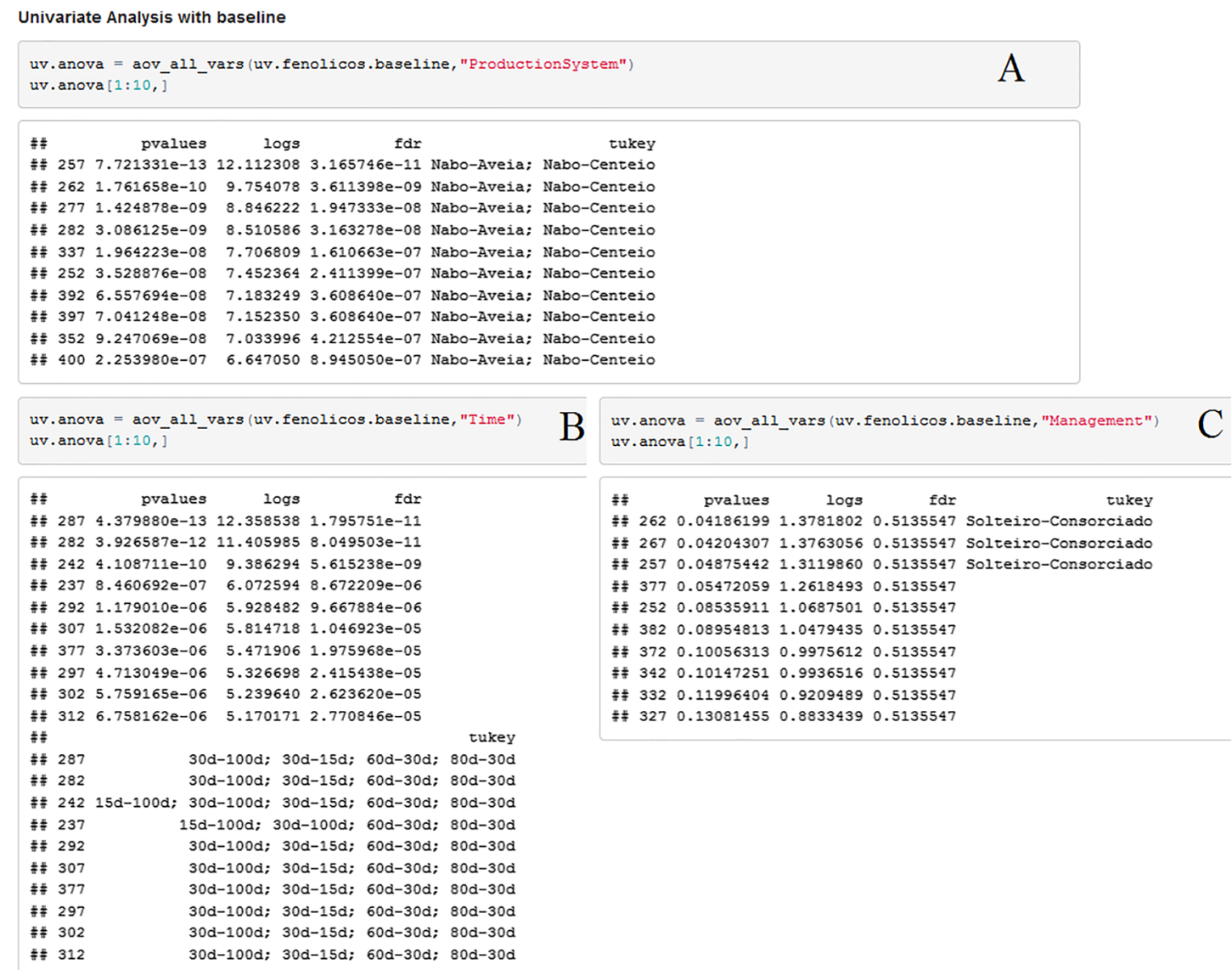

Figure 6: Univariate analysis performed on the UV-vis spectra and the wavelengths that contributed the most for the clustering according to plant species (A), period of sampling (B) and crop management system (C).

broken down within 15 days after rolling. In contrast, rye and black oat, due to their higher fiber content, take around 20 days to be broken down [36, 38, 39]. On the whole, the three species have started breaking down 15 days after rolling. Therefore, the phenolic compounds with allelopathic potential detected in plant tissues at 60, 80 and 100 DAS may have been released into the soil [36] by many ways, such as leaching, volatilization and dry matter decomposition by soil microorganisms [40], leading to the spectral profile changes observed.

On the other hand, when samples were analyzed considering the management system, no discrimination between single crop or intercrop was observed (Figures 4 and 5C), except in the wavelengths 257, 263 and 267 $\mathrm{nm}(p<0.05)$ (Figure 6C). The phenolic compounds produced by one plant species may interfere on the growth of other plant species, thus we aimed to investigate if intercropping would restrict one or both intercropped species, and if intercropping would result in distinct spectral profiles and phenolic compounds content. Our results suggest that intercropping species is a good option, as the sum of the phenolic compounds released by intercropped species could magnify their allelopathic potential, in addition to the physical barrier effect they play on the soil [36, 39, 41].

Besides PCA, supervised machine learning models PLS and knn were applied to spectral region 200-800 $\mathrm{nm}$ aiming to check the accuracy to classify samples according to species, time of cultivation and management system (Table 1). The prediction accuracy reached $75 \%$ when spectra were classified according to the species, which was higher than the accuracy for the classification according to the time of cultivation $(62 \%)$ and the management system (52\%) (Table 1). The wavelengths in the region of phenolic compounds' 
Table 1: Classification accuracy of predictive models PLS and knn according to plant species, time of cultivations and crop management system of UV-vis spectra from Secale cereale L, Avena strigosa L. and Raphanus sativus L. extracts.

\begin{tabular}{lrrr}
\hline Accuracy & \multicolumn{3}{c}{ Classification } \\
\cline { 2 - 4 } & Species & Time & Management systems \\
\hline pls & 75.68 & 66.19 & 56.46 \\
kmn & 72.23 & 67.84 & 52.98 \\
\hline
\end{tabular}

Table 2: Individual relative contribution (\%) of the 10 wavelengths, in UV-vis, most relevant to the classification by species, of the samples the cover crops Avena strigosa L. (black oat), Secale cereale L. (rye) and Raphanus sativus L. (oilseed radish).

\begin{tabular}{|c|c|c|c|}
\hline Wavelength (nm) & Black oat & Rye & Oilseed radish \\
\hline 200 & 53.84 & 86.96 & 100.00 \\
\hline 201 & 26.30 & 82.85 & 76.55 \\
\hline 202 & 15.25 & 84.69 & 70.64 \\
\hline 203 & 11.95 & 69.57 & 57.16 \\
\hline 204 & 12.49 & 62.18 & 53.24 \\
\hline 275 & 32.70 & 47.08 & 56.30 \\
\hline 276 & 34.67 & 49.30 & 59.05 \\
\hline 277 & 34.67 & 49.30 & 59.90 \\
\hline 278 & 33.09 & 47.14 & 57.35 \\
\hline 279 & 32.28 & 45.36 & 55.91 \\
\hline
\end{tabular}

absorption (200-400 nm) were the most relevant for that discrimination (Table 2). The results indicate that phenolic profiles are more distinguishable due to the species rather than phenological stage, time of cultivation or management system. By building predictive models such as PLS and knn, it is possible to assess how accurate an arbitrary previous classification is [42].

\section{Conclusion}

The analytical approach used in this work, i.e. the spectral data obtained via UV-vis spectroscopy in association with chemometric methods in $\mathrm{R}$ language with package specmine, enabled to discriminate and classify the samples based on their biochemical features.

The exploratory analysis of the spectra by multivariate analysis was efficient to show a trend of clustering between the treatments, discriminating the chemical profile of oilseed radish from black oat and rye.

Differences between the phenolic profiles were more evident regarding to the plant species rather than the period of cropping, phenologic stage or crop system, i.e. single or intercropped. This is corroborated by pls and knn results, which discriminated species with $75 \%$ accuracy, especially in the spectral region of phenolic compounds.

Regarding the periods of cropping, PCA analysis showed that the most evident discrimination occurred for rye and black oat at 30 days after rolling, in contrast to other sampling periods when black oat and rye were in the phenological stages of elongation, flowering and vegetative development, and the oilseed radish blossoming and grain ripening.

Acknowledgements: "To the Coordination of Superior Level Staff Improvement - Brazil (CAPES) for the doctorate fellowship and to the National Council for Scientific and Technological Development (CNPq) - Call MCTI/MAPA/MDA/MEC/MPA/CNPq No 81/2013 for financial support.” 
Author contribution: All authors have accepted responsibility for the entire content of this manuscript and approved its submission.

Research funding: Coordenação de Aperfeiçoamento de Pessoal de Nível Superior (CAPES), Conselho Nacional de Desenvolvimento Científico e Tecnológico do Ministério da Ciência, Tecnologia e Inovação, 81/2013.

Conflict of interest statement: Authors state no conflict of interest.

\section{References}

1. Harborne JB. Phytochemical methods, 3rd ed. London: Chapman \& Hall; 1998.

2. Moresco R, Uarrota V, Pereira A, Tomazzoli M, Nunes EC, Peruch LAM, et al. UV-visible scanning spectrophotometry and chemometric analysis as tools for carotenoids analysis in cassava genotypes (ManihotesculentaCrantz). J Integr Bioinform 2015;12:1-12.

3. Taiz L, Zeiger E. Fisiologia vegetal, 4th ed. Porto Alegre (RS): ARTMED; 2009.

4. Hagemann TR, Benin G, Lemes C, Marchese JA, Martin TN, Pagliosa ES, et al. Potencial alelopático de extratos aquosos foliares de aveia sobre azevém e amendoim-bravo. Bragantia 2010;69:509-18.

5. Inderjit WDA, Karban K, Callaway RM. The ecosystem and evolutionary contexts of allelopathy. Trends Ecol Evol 2011;26:655-62.

6. Boydston R, Hang A. Rapeseed (Brassica napus) green manure crop suppresses weeds in potato (Solatium tuberosum). Weed tech 1995;9:669-75.

7. Hanhineva K, Pihlava J, Mykkanen H, Poutanen K. Chapter 8 - benzoxazinoids in rye and rye-derived products. In: Rye and health. Elsevier; 2014:121-9 pp.

8. Tanwir F, Dionisio G, Adhikari KB, Fomsgaard IS. Biosynthesis and chemical transformation of benzoxazinoids in rye during seed germination and the identification of a rye Bx6-like gene. Phytochemistry 2017;140:95-107.

9. Heinio R, Liukkonen K, Myllyma O, Pihlava J, Adlercreutz H, Heinonen S, et al. Quantities of phenolic compounds and their impacts on the perceived flavour attributes of rye grain. Cereal Sci 2008;47:566-75.

10. Mota RDP, Castro TLC, Zuppa TO, Rosa EV. Quantificação Espectrofotométrica de Flavonóides em Rabanete (Raphanus sativus). Rev Port Quim 2009:112-15. https://doi.org/10.19142/rpq.v3i5.93.

11. Pilatti F, Costa C, Rocha M, Maraschin M, Viana AM. UV-visible spectrophotometry-based metabolomic analysis of Cedrela fissilis velozzo (Meliaceae) calluses: a screening tool for culture medium composition and cell metabolic profiles. Adv Intell Syst Comput 2015;375:29-36.

12. Ferreira MMC, Antunes AM, Melgo MS, Volpe PLO. Chemometrics I: multivariate calibration, a tutorial. Quim Nova 1999;22:724-31.

13. Tomazzoli M, Pai Neto RD, Moresco R, Westphal L, Somensi-Zeggio A, Specht L, et al. Discrimination of Brazilian propolis according to the seasoning using chemometrics and machine learning based on UV-Vis scanning data. J Integr Bioinform 2015;12:15-26.

14. Casale LB, Giordani P, Mariotti MG, Malaspina P. NIR spectroscopy as a tool for discriminating between lichens exposed to air pollution. Chemosphere 2015;134:355-60.

15. Maraschin M, Somensi-Zeggio A, Oliveira SK, Kuhnen S, Tomazzolli MM, Raguzzoni JC, et al. Metabolic profiling and classification of propolis samples from southern Brazil: an NMR-based platform coupled with machine learning. J Nat Prod 2016;79:13-23.

16. Sabir A, Rafi M, Darusman LK. Discrimination of red and white rice bran from Indonesia using HPLC fingerprint analysis combined with chemometrics. Food Chem 2017;221:1717-22.

17. Afonso T, Moresco R, Uarrota VG, Navarro BB, Nunes EC, Maraschin M, et al. UV-vis and CIELAB based chemometric characterization of Manihot esculenta Carotenoid contents. J Integr Bioinform 2017;14:1.

18. Pilatti FK, Ramlov F, Schmidt EC, Costa C, Oliveira EG, Bauer CM, et al. Metabolomics of Ulva lactuca Linnaeus (Chlorophyta) exposed to oil fuels: Fourier transform infrared spectroscopy and multivariate analysis as tools for metabolic fingerprint. Mar Pollut Bull 2016;114:831-6.

19. Kuhnen S, Ogliari JB, Dias PF, Boffo EF, Correia I, Ferreira AG, et al. ATR-FTIR spectroscopy and chemometric analysis applied to discrimination of landrace maize flours produced in southern Brazil. I. J Food Sci Technol 2010;45:1673-81.

20. Kuhnen S, Ogliari JB, Dias PF, Santos MS, Ferreira AG, Bonham CC, et al. Metabolic fingerprint of Brazilian maize landraces silk (Stig-ma/Styles) using NMR spectroscopy and chemometric methods. J Agric Food Chem 2010;58:2194-200.

21. Neto BB, Scarmínio IS, Bruns RE. Anos de quimiometria no Brasil. Quim Nova 2006;29:1401-6.

22. Soil Survey Staff. Keys to soil taxonomy, 11th ed. Washington DC: USDA-NRCS; 2010.

23. R Development Core Team. R: a language and environment for statistical computing. Vienna: Austria: R Foundation for Statistical Computing; 2010. 
24. Costa C, Maraschin M, Rocha M. R package version 1.0: specmine: metabolomics and spectral data analysis and mining; 2015.

25. Silva AA, Nascimento ESP, Cardoso DR, Franco DW. Identificação de extratos etanólicos de madeiras utilizando seu espectro eletrônico de absorção e análise multivariada. Quim Nova 2012;3:556-63.

26. Paganotti RSN, Rezende JC, Barbeira PJS. Discrimination between producing regions of Brazilian propolis by UVVIS spectroscopy and partial least squares discriminant analysis. Curr Anal Chem 2014;10:537-44.

27. Alder M, Alon U. Fold-change detection in biological systems. Curr Opin Struct Biol 2018;8:81-9.

28. Klajan VM, Gutkoski LM, Fiorentini AM, Elias MC. Compostos antioxidantes da aveia. Curr Agri Sci Tech 2012;18:292-303.

29. Rehman MU, Hussain M, Aali M, Mustafa CB, Shafi J, Iqbal F. Allelopathy of Brassicas. A review. Sci. Agric. 2013;3:46-53.

30. Souza AM, Breitkreitz MC, Filgueiras PR, Rohwedder JJR, Poppi RJ. Experimento didático de quimiometria para calibração multivariada na determinação de paracetamol em comprimidos comerciais utilizando espectroscopia no infravermelho próximo: um tutorial, parte II. Quím. Nova 2013;36:1057-65.

31. Barros Neto B, Scarminio IS, Bruns RE. 25 anos de quimiometria no Brasil. Quím. Nova 2006;29:1401-6.

32. Cartea ME, Francisco M, Soengas P, Velasco P. Phenolic compounds in Brassica vegetables. Molecules 2011;6:251-80.

33. Blazevic I, Mastelic J. Glucosinolate degradation products and other bound and free volatiles in the leaves and roots of radish (Raphanus sativus L.). Food Chem 2009;113:96-102.

34. Weidner S, Aamarowicz, Karamác M, Fraczek E. Changes in endogenous phenolic acids during development of Secale cereale caryopses and after dehydration treatment of unripe rye grains. Plant Physiol Biochem 2000;38:595-602.

35. Andreasen MF, Christensen LP, Meyer AS, Han-sen A. Content of phenolic acids and ferulic acid dehydrodimers in 17 rye (Secale cereale L.) varieties. J Agric Food Chem 2000;48:2837-42.

36. Souza M, Comin JJ, Kurtz C, Lovato PE, Lima AP, Kuhnen S. Phenolic compounds with allelopathic potential of Secale cereale and Raphanus sativus grown under an agroecological no-tillage systems. Planta Daninha 2019;37:1-12.

37. Macias FA, Molinillo JMG, Varela RM, Galindo JCG. Allelopathy - a natural alternative for weed control. Pest Manag Sci 2007;63:327-48.

38. Martins RP, Comin JJ, Gatiboni LC, Soares CRF, Brunetto G. Nitrogen mineralization of cover plant litter, intercropped or not, in a soil with a history of onion plantation. Rev Ceres 2014;61:587-96.

39. Oliveira RA, Brunetto G, Loss A, Gatiboni LC, Kurtz C, Muller VM, et al. Cover crops effects on soil chemical properties and onion yield. Rev Bras Cienc Solo 2016;40:1.

40. Crusciol CA, Cottica RL, Vale Lima E, Andreotti M, Moro E, Marcon E. Persistência de palhada e liberação de nutrientes do nabo-forrageiro no plantio direto. Pesqui Agropecuária Bras 2005;40:161-8.

41. Souza M, Muller VJ, Kurtz C, Brunetto G, Comin JJ. Weed Emergence in a soil with cover crops in an agroecological no-tillage system. Planta Daninha 2018;36:1-9.

42. Worley B, Powers R. Multivariate analysis in metabolomics. Curr Metabolomics 2013;1:92-107.

Supplementary Material: The online version of this article offers supplementary material (https://doi.org/10.1515/jib-20190056). 